\section{№. 4655 January 17,1959}

monkey are now more variable than in the mainland variety. Although the possibility cannot be excluded that this complex of change has resulted from the direct action of a changed environment on an unaltered genetic constitution, parallels with complexes of change recorded in laboratory experiments with lower animals suggest that the differences may have, as a basis, changes in systems of multiple genes. In this case, the observations would represent an example, at present unique, of the effect of selective forces upon primate population.

E. H. Ashton

\title{
WOMEN IN ENGINEERING
}

$\mathrm{P}$ ROBABLY the most persuasive case for the employment of professional women in industry has been made by the Women's Engineering Society. Unlike other women advocates who rely either on wistful laments or on emotional over-statements of unestablished truths, the Women's Engineering Society bases its case on hard-won knowledge of industry and on the records of those courageous and enterprising women engineers who have already made successful careers for themselves in industry. In a booklet prepared by members of the Careers Panel of the Society, it is shown that there is now no reason why a girl with talent and determination should not embark on an engineering career with every prospect of success (Training and Opportunities for Women in Engineering, 25 Fouberts Place, London, W.1. 3s. 6d.). She is advised, however, to equip herself fully with formal qualifications, like membership of professional institutions and those obtained by examination, such as a university degree in engineer. ing or a Higher National Certificate. "Engineering training has two distinct components, theory and practice, and both are equally necessary to the would-be engineer. The former can be obtained in
Universities and Technical Colleges, while, for most branches of the profession, the best practical training is provided in industry." It is in obtaining this practical training that the girl student may find herself at a disadvantage compared with her brother. Entry into certain branches of engineering is easier than into others, and there is more prejudice against the employment of women in certain positions than in others. The new branches of engineering such as aeronautics, electrical and electronic engineering, or heating and ventilating, offer an easier entry to women than do the older branches such as marine or locomotive engineering, naval architecture or civil engineering.

There is still a prejudice against putting women in control of large numbers of men, and few firms the employees of which are mostly male would consider appointing a woman as works manager or foreman. There is far less prejudice against the employment of women in scientific work, design or research.

The booklet describes the training and qualifications required in many branches of engineering as well as the posts available when training is complete.

\section{WATER POLLUTION RESEARCH, 1957*}

$\mathrm{M}$ UCH of this tightly packed report will be of interest only to those who are directly concerned with sewage treatment and pollution, and the thirty-two papers published by members of the staff during the year have nearly all appeared in technical journals. Some of the work is of wider appeal, and merits fuller mention than the rest in a journal of general science such as Nature.

Various calculations have been made to find the most economical way of improving the Thames estuary. Aeration of some of the worst inflows has been suggested, but it is shown that the effect of this would not be great. An increase in temperature would lead to an immediately greater oxygen deficit but a corresponding amelioration farther down the river. It has been found that, especially at higher temperature, nitrate may be reduced before the concentration of oxygen approaches zero, a hitherto unsuspected complication in calculations of this kind. Even after the completion by the London County Council in about 1962 of alterations and extensions to its sewage works, the Thames will still be foul. Sulphide, perhaps, will no longer be formed in the central reaches of the estuary, but oxygen concentration will be low.

Fig. 13 of the report shows how oxygenation of water passing over a weir increases with the height of

* Department of Scientiflc and Industrial Research. Water Pollution Research 1957: The Report of the Water Pollution Research Board with the Report of the Director of the Water Pollution Research Laboratory. Pp. iv $+\mathbf{1 0 0}+4$ plates. (London: H.M. Stationery Office, 1958.) 68. net. the weir, rapidly at first but gradually more slowly, a 9-foot weir, the highest tested, being only slightly more advantageous than one 8 feet high. The effect depends also on the depth of the basin into which the water falls; with a 5-foot fall the concentration of oxygen increases quite markedly up to a depth of 8 inches, but thereafter is the same for all depths. Another experimental set-up of general interest is the channel for studying temperature gradients. It is 500 feet long and is made by setting baffles across a tank. The object is to study the behaviour of fish in a temperature gradient; but first it will be necessary to study the nature of the gradient under different conditions of flow, humidity and initial temperature. Some figures are presented here, but it is hoped that more will be fortheoming and their relation to the results of theoretical calculations discussed. The continuous recorder for dissolved oxygen, on its way to becoming a standard instrument, has been developed and improved by the incorporation of a device for automatic temperature compensation, which is described.

The amount of effluent necessary for a satisfactory test of toxicity is inconveniently large if the fish used is more than about 1 inch long, and foreign fish have been used since no British species is as small as this when adult. The apparatus designed for routine tests is described and figured. Zinc is shown to be toxic at lower concentration in soft than in hard water, rainbow trout, for example, dying in less than three days in 0.5 p.p.m. zinc in soft water and sur. 